\title{
APRENDIZAGEM DE LÍNGUA INGLESA: \\ UMA (AUTO)ANÁLISE
}

\author{
Lucas Maciel de Albuquerque \\ Giêdra Ferreira Cruž
}

RESUMO: O presente trabalho objetivou a realização de uma (auto)análise de uma narrativa de aprendizagem da língua inglesa redigida no momento em que o narrador cursava o semestre inicial de um Curso de Letras. Ao longo da (auto)análise, mobilizamos conceitos relacionados à três categorias de análise: a) manifestações da autonomia do aprendiz; b) os propiciamentos evidenciados na relação entre o aprendiz e os ambientes de aprendizagem; c) situações em que o uso de tecnologias digitais se integrou aos esforços de aprendizado da língua inglesa. Percebemos, com a seleção de excertos representativos da narrativa, que o narrador tornou-se gradualmente mais autônomo em relação à sua própria aprendizagem ao longo da sua trajetória, escolhendo recursos tecnológicos e ambientes de aprendizagem mais adequados aos seus gostos e motivações para aprender a língua. Além disso, percebemos que a (auto)análise proporcionou ao autor da narrativa a possibilidade de ressignificar a sua trajetória com a língua e de refletir sobre como a sua aprendizagem pode influenciar a sua atuação profissional.

PALAVRAS-CHAVE: Autonomia; Narrativas de aprendizagem; Propiciamentos; Uso de tecnologias digitais.

\section{Introdução}

O estudo da autonomia no contexto de aprendizagem de línguas tem ganhado relevância na Linguística Aplicada desde a década de 1980 (LUZ, 2009). Tem-se notado uma mudança de foco dos trabalhos dessa área, em que cada vez mais estudos se propõem

\footnotetext{
* Mestrando Em Letras: Cultura, Educação e Linguagens pela Universidade Estadual do Sudoeste da Bahia (Uesb).

** Professora Titular da Universidade Estadual do Sudoeste da Bahia (Uesb). Doutora em Letras e Linguística pela Universidade Federal da Bahia (Ufba).
} 
a abordar a perspectiva do aprendiz sobre o processo de ensino-aprendizagem e a sua capacidade de tornar-se mais responsável por sua própria aprendizagem (HOLEC, 1981).

A ascensão da abordagem comunicativa de ensino de línguas foi essencial para essa mudança de paradigma, como apontado por Paiva (2005, 2006). O entendimento relativamente recente segundo o qual a língua deve ser utilizada como meio de comunicação dentro da sala de aula favoreceu a elaboração de materiais e métodos mais flexíveis e que prezavam pelo desenvolvimento das habilidades comunicativas dos aprendizes. Para o professor, isso significou uma maior liberdade para realizar atividades que julgavam ser mais relevantes para sua prática; para o aprendiz, passaram a existir mais oportunidades de se responsabilizar por sua própria aprendizagem. Em outras palavras, o aprendiz passou a ter mais chances de se tornar autônomo.

Com essa nova perspectiva sobre a aprendizagem de línguas em que a figura do aprendiz se torna mais importante, a voz do aprendiz também ganha relevância. Nesse sentido, a produção de narrativas de aprendizagem em que o aprendiz revela suas percepções sobre seus encontros e desencontros com uma língua estrangeira são de grande valor, por explicitar de forma bastante pessoal as relações do aprendiz com a língua. Apoiado na liberdade de expressão oferecida pelo gênero narrativa, o aprendiz pronunciase sobre sua relação com a língua de maneira "pessoal, individual, idiossincrática, íntima, subjetiva, temporal, circunstancial, casual, esporádica, episódica e assistemática” (RAJAGOPALAN, 2010, p. 13).

Neste artigo, objetivamos discutir a trajetória de aprendizagem de um aprendiz autônomo de Inglês. Para isso, partimos de uma narrativa de aprendizagem escrita por esse aprendiz no início da sua graduação em Letras.

Ressaltamos que um dos autores do presente trabalho é esse aprendiz autônomo, no início da sua trajetória acadêmica. Assim, trata-se, também, de um trabalho de (auto)análise de narrativa de aprendizagem. Baseamo-nos na ideia de que a atribuição de significados a acontecimentos passados oferece uma oportunidade de contextualizar tais acontecimentos, evidenciando fatos importantes que podem não ter sido percebidos pelo 
sujeito (FREITAS; GALVÃO, 2007). A investigação realizada se pauta em três categorias de análise da referida narrativa: a) manifestações da autonomia do aprendiz; b) os propiciamentos evidenciados na relação entre o aprendiz e os ambientes de aprendizagem; c) situações em que o uso da tecnologia se integrou ao aprendizado da língua inglesa.

A seguir, partimos do aporte teórico acerca dos temas autonomia, propiciamento e tecnologias digitais, para, em seguida, procedermos a (auto)análise da narrativa de aprendizagem.

\section{Autonomia}

A autonomia do aprendiz no contexto de ensino de línguas tem recebido destaque nos estudos recentes da Linguística Aplicada. Com o novo foco comunicativo das recentes abordagens sobre o ensino e aprendizagem de línguas surge a figura do aprendiz autônomo. Surge, também, o interesse em entender como atitudes autônomas se instauram dentro e fora da sala de aula, e como tais atitudes contribuem para a construção do conhecimento do aprendiz.

Mas o que exatamente significa ser autônomo? A conceituação de autonomia no contexto de ensino e aprendizagem de línguas tem sido ponto de discussão por muitos anos (PAIVA, 2006). Neste trabalho, não realizamos uma discussão exaustiva sobre a definição de autonomia ao longo da vasta literatura disponível sobre o assunto; pretendemos, no entanto, delinear certas características do conceito de autonomia que possam nos ajudar na reflexão sobre a aprendizagem de Inglês na narrativa de aprendizagem que nos propomos discutir.

Como nos aponta Paiva (2006), “definir autonomia não é tarefa fácil” (PAIVA, 2006, p. 81). Ser autônomo não se resume à autoinstrução (LITTLE, 2007), nem à habilidade de se responsabilizar pela própria aprendizagem (HOLEC, 1981). O conceito de autonomia deve ser elaborado de forma a abarcar as suas mais diversas manifestações. Para Dickinson (1994), a autonomia na aprendizagem é uma questão de atitude do aprendiz em relação à sua própria aprendizagem. Segundo o autor, o aprendiz autônomo é o que 
toma decisões sobre aspectos da sua aprendizagem, tornando-se responsável pelo seu aprendizado.

Scharle e Szabó (2000) dedicam atenção especial às maneiras com que o professor pode ajudar o aluno a desenvolver sua autonomia. As autoras atrelam o desenvolvimento da autonomia do aprendiz ao seu senso de responsabilidade sobre sua própria aprendizagem - dessa forma, um aprendiz que "aceita a ideia de que seus próprios esforços são cruciais para o progresso na aprendizagem e que age de acordo com essa ideia" (SCHARLE; SZABÓ, 2000, p. 3: tradução nossa) é um aprendiz responsável. Essas autoras apontam três grandes etapas no processo gradual de desenvolvimento da autonomia do aprendiz: primeiro, é necessário conscientizá-lo sobre seus processos internos de aprendizagem; segundo, introduzem-se novas atitudes e atividades que evidenciem a responsabilidade do aprendiz sobre sua própria aprendizagem; por último, realizam-se atividades em que os aprendizes gozam de maior liberdade, assumindo responsabilidades antes limitadas à figura do professor.

Desse modo, essa responsabilidade não é exclusiva do aprendiz, mas sim compartilhada com o professor (BENSON; VOLLER, 1997). Nesse sentido, a figura do docente é essencial para o desenvolvimento da autonomia dos alunos. Conforme afirma Dickinson (1994, p.12 tradução nossa) ${ }^{1}$, "autonomia não é uma ameaça ao papel ou ao trabalho do professor, [...] preparar aprendizes para a autonomia é um processo de ensinoaprendizagem em que a responsabilidade é compartilhada entre professores e aprendizes". Tal processo objetiva que os aprendizes se tornem progressivamente mais autossuficientes.

Em consonância com os autores mencionados anteriormente, enfatizamos que a autonomia do aprendiz não entra em conflito com o papel do professor no processo de ensino-aprendizagem, uma vez que o aprendiz autônomo necessita do professor no sentido de sensibilizá-lo sobre sua capacidade de desenvolver sua autonomia.

\footnotetext{
${ }^{1}[. .$.$] my view of autonomy is not a threat to the teacher's role or the teacher's job. The result of preparing learners$ for autonomy is a teaching/learning process in which responsibility is shared between teachers and learners, with learners becoming progressively more self-sufficient.
} 
Como mencionamos anteriormente, há uma vasta literatura sobre autonomia e suas conceituações. Contudo, nos alinhamos à definição de Paiva (2006), por sintetizar o que já foi dito sobre autonomia ao longo dos anos e pelo fato de ir além desses conceitos préestabelecidos ao pontuar que,

autonomia é um sistema sócio-cognitivo complexo, que se manifesta em diferentes graus de independência e controle sobre o próprio processo de aprendizagem, envolvendo capacidades, habilidades, atitudes, desejos, tomadas de decisão, escolhas, e avaliação tanto como aprendiz de língua ou como seu usuário, dentro ou fora da sala de aula. (PAIVA, 2006, p. 88-89)

Como pode ser visto, essa definição denota o caráter complexo que envolve a autonomia do aprendiz, pois aponta que ela se manifesta de diferentes formas e indica que a autonomia envolve aspectos que não estão limitados ao espaço escolar. Assim, o aprendiz autônomo pode expandir os seus espaços de aprendizagem para além das paredes da sala de aula.

\section{Propiciamento (affordance)}

Dentre as inúmeras facetas do processo de aprendizagem de línguas estrangeiras, chamamos atenção para o conceito de propiciamento (affordance).

Como nos apontam Aronin e Singleton (2012), a noção de propiciamento não foi inicialmente desenvolvida no campo das ciências humanas, mas sim no campo da ecologia. Nesse contexto, Gibson (1986) definiu propiciamento como os elementos que o ambiente oferece ou provê ao animal, e que podem facilitar ou dificultar sua sobrevivência. É Van Lier (2004) quem transporta esse conceito para os estudos sobre ensino-aprendizagem de línguas. Propiciamento, nas palavras desse autor, é "um relacionamento entre um organismo (no nosso caso, um aprendiz) e o ambiente, que sinaliza uma oportunidade ou 
uma inibição para a ação"2 (VAN LIER, 2004, p. 4: tradução nossa). Assim sendo, propiciamento define-se como "demandas e exigências, oportunidades e limitações, rejeições e atrações, habilidade e restrições [...]a relação entre as propriedades do ambiente e o aprendiz ativo" (VAN LIER, 2004, p. 4, grifos nossos). Determinadas condições do ambiente propiciam determinados recursos para o sujeito incluído em tal ambiente. Entretanto, o conceito de propiciamento depende de uma movimentação ativa do sujeito, como indicado por Gomes e Souza (2017),

[...] ainda que o ambiente ofereça ao agente inúmeros propiciamentos, este só vai utilizá-los como oportunidade de ação de acordo com a maneira que os significar, isto é, se perceber neles relevância para que possa aprender melhor (GOMES; SOUZA, 2017 , p. 72).

A partir do exposto por Gomes e Souza (2017), vemos que é apenas a partir da interação entre ambiente e sujeito que se torna possível falar, de fato, sobre propiciamento. Sendo que, no contexto escolar, o principal responsável por estabelecer as condições favoráveis à emergência de propiciamentos é o professor (KORDT, 2016). Desse modo, as propriedades do ambiente em que se insere o aprendiz de língua estrangeira não são estanques. Os recursos que o aprendiz tem à disposição mudam constantemente, e tal fato exerce grande influência sobre sua aprendizagem. Daí decorre que "em um mesmo ambiente, propiciamentos bastante diferentes podem emergir para indivíduos diferentes, ou para um mesmo indivíduo em momentos distintos 3" (KORDT, 2016, p. 2: tradução nossa).

Os propiciamentos podem se manifestar em diferentes maneiras, algumas das quais listamos a seguir, com base em Aronin e Singleton (2012),

2 " [...] a relationship between an organism (a learner, in our case) and the environment, that signals an opportunity for or inhibition of action"

${ }^{3}[\ldots]$ in the same environment widely differing affordances can emerge for different individuals or for the same individual at different times 
eventos e acontecimentos, pressupostos e conhecimentos comuns, bibliotecas e prédios escolares, currículos, conhecimento de outras línguas que não a língua alvo, o grau de profissionalismo dos professores de línguas, a disponibilidade de livros didáticos e dicionários para os aprendizes[...]. Todas essas coisas, que são tão diferentes e que podem ser tangíveis ou intangíveis, são propiciamentos $^{4}$. (ARONIN; SINGLETON, 2012, p. 319: tradução nossa)

Esse grande número de possíveis manifestações de propiciamentos citados anteriormente nos incita a refletir sobre os diferentes propiciamentos com que o aprendiz tem contato ao longo da sua trajetória de aprendizagem. Nesse sentido, acreditamos haver uma necessidade de ouvir a voz do aprendiz sobre sua própria aprendizagem e sobre as condições nas quais ela ocorre.

Assim, concordamos com Paiva (2010), quando esta afirma que "narrar uma experiência de aprendizagem de língua estrangeira é necessariamente discorrer sobre propiciamentos" (p. 157). Por meio da escrita de narrativas de aprendizagem, o aprendiz pode expressar suas satisfações ou insatisfações com os propiciamentos a que tem acesso. Essa relação se torna ainda mais evidente ao falarmos de aspectos autônomos de uma aprendizagem de língua estrangeira.

\section{Tecnologias digitais}

Os mais variados tipos de tecnologia já foram e continuam sendo utilizados para se ensinar e aprender línguas estrangeiras (PAIVA, 2015). Desde gramáticas normativas a tecnologias de áudio e vídeo como televisões e aparelhos de som, existe um grande número de instrumentos que servem como acessórios para o processo de aprendizagem. Mais recentemente, observamos a ascensão das tecnologias digitais, que se valem da digitalização

\footnotetext{
${ }^{4}$ Events and happenings, assumptions and common knowledge, school buildings and libraries, curricula, knowledge of languages other than target languages, the degree of professionalism of language teachers, the availability of textbooks and dictionaries for learners[...]. All of these so widely different things, which may be tangible or intangible, are affordances.
} 
de conteúdos para, entre outras coisas, facilitar a integração entre velhas e novas mídias e para integrar os indivíduos que fazem uso dessas mídias (SANTOS et al., 2018). Entre as tecnologias digitais de maior expressão, destacamos o computador e a Internet.

O computador constitui-se, como apontam Braga e Costa (2000), uma importante "ferramenta para o ensino e meio para aprendizagem e prática da língua alvo" (BRAGA; COSTA, 2000, p. 62). Dentre as diferentes possibilidades oferecidas pelo computador, estão novas formas de escrever e editar textos, gravar e reproduzir diferentes tipos de áudio, etc. É de se esperar que a introdução de uma ferramenta tão versátil no contexto de ensinoaprendizagem impacte profundamente as relações que estabelecem entre aluno, professor e língua.

Além disso, temos a grande inovação tecnológica que é a Internet. O acesso rápido ao enorme acervo de informações contidas na rede transformou profundamente a condição humana- a comunicação online é rápida, abrange um território imenso e reúne pessoas de todo o mundo. O uso de aplicativos e redes sociais como Facebook, Whatsapp, Instagram e Twitter tornou-se cotidiano para grande parte da população mundial. Essa nova realidade traz uma complexa gama de novas formas de interagir, dialogar e aprender.

É nesse contexto que concordamos com Pinho e Lima (2013), que defendem que

[...] o professor de línguas deve conhecer o potencial das tecnologias digitais, adicionando a elas objetivos métodos educacionais claros para serem capazes de criar atividades que correspondam com suas concepções docentes ${ }^{5}$ (PINHO, LIMA, 2013, p. 732: tradução nossa).

A presença das tecnologias digitais em nossa sociedade precisa ser pautada pelos professores, de forma a integrar tais tecnologias em sua atividade docente. No entanto, isso não quer dizer que são as tecnologias que ditarão a abordagem de ensino do professor. $\mathrm{Na}$

\footnotetext{
5 "the language teacher should know the potential of digital technologies, adding to them clear educational objectives and methods in order to be able to create tasks that match their teaching conceptions"
} 
verdade, é o docente que adequa e incorpora as tecnologias digitais à sua prática. Assim sendo, advogamos que o uso de diferentes artefatos tecnológicos pode estar diretamente ligado à promoção da autonomia do aprendiz. Nesse sentido, há um grande número de acessórios tecnológicos ao processo de aprendizagem, como nos aponta Paiva (2006):

Material impresso, fotocópias, dicionários, recursos visuais, gravadores, laboratórios de línguas, vídeos, computadores, ferramentas da Internet [...] DVDs, e CD-roms são alguns exemplos de artefatos culturais que podem emancipar os alunos em suas tentativas rumo à autonomia (PAIVA, 2006, p. 114).

Diante do exposto, percebemos que são vários os elementos tecnológicos que podem contribuir para a promoção da autonomia do aprendiz. Tais elementos podem ser utilizados pelo professor em sala de aula ou descobertos pelo próprio aprendiz quando ele exerce sua autonomia fora do ambiente escolar.

Após evidenciarmos a relação entre a autonomia do aprendiz e os diferentes propiciamentos, que se estabelecem na relação entre esse aprendiz e os ambientes de aprendizagem a que tem acesso, ressaltamos a importância das tecnologias digitais na aprendizagem de línguas e no exercício da autonomia do aprendiz. A seguir, apresentamos a metodologia utilizada neste estudo.

\section{Metodologia}

Nesta seção, apresentamos a metodologia utilizada neste trabalho. No que se refere à narrativa de aprendizagem discutida, explicitamos que esta foi escrita por um dos autores deste artigo, quando ainda cursava a graduação em Letras Modernas em uma Universidade do interior da Bahia. Nesse período, ele foi convidado por uma professora de língua inglesa, da referida Universidade, a escrever uma narrativa sobre a sua aprendizagem de Inglês. Com a finalização da redação da narrativa, em agosto de 2013, havia uma proposta de converter essa produção de texto em um trabalho científico, mas essa proposta não se concretizou. Atualmente, com um novo olhar, esse aprendiz, em parceria com a coautora deste trabalho, 
realizou a (auto)análise da sua narrativa de aprendizagem, redigida no início da graduação.

Assim sendo, este trabalho configura-se, também, como uma (auto)análise de narrativa de aprendizagem, em que o autor da narrativa se debruça sobre sua própria escrita a fim de ressignificar sua trajetória de aprendizagem. Acreditamos, em concordância com o dito por Cunha (1997), que "[t]omando-se distância do momento de sua produção [da narrativa], é possível, ao 'ouvir' a si mesmo ou a 'ler' seu escrito, que o produtor da narrativa seja capaz [...] de ir teorizando a própria experiência” (CUNHA, 1997, p. 188).

A partir da leitura cuidadosa da narrativa, percebemos a existência de três temas recorrentes ao longo da narrativa, temas esses que retomamos neste artigo como categorias de análise, a saber: a) manifestações da autonomia do aprendiz; b) os propiciamentos evidenciados na relação entre o aprendiz e os ambientes de aprendizagem; c) situações em que o uso da tecnologia se integrou aos esforços de aprendizado da língua inglesa.

Dessa forma, a análise partiu da seleção de excertos que nos oportunizaram discutir questões relacionadas às diferentes categorias propostas para o nosso estudo. Os excertos foram, então, agrupados de acordo com as categorias às quais pertenciam e acrescidos de observações pautadas na literatura revisada.

Tendo explicado o percurso metodológico da produção deste trabalho, apresentamos a seguir a narrativa, na íntegra, e logo após, a discussão do texto.

\section{A narrativa}

(1) Meu primeiro contato significativo com o inglês de que eu consigo me lembrar aconteceu ainda no ensino primário, na $3^{\mathrm{a}}$ ou $4^{\mathrm{a}}$ série (hoje, $4^{\circ}$ ou $5^{\circ}$ ano do ensino fundamental). Nós tínhamos aulas de inglês toda semana, ou quinzenalmente (é difícil lembrar com exatidão). As aulas não tinham um caráter bastante rígido, o professor apenas ensinava um vocabulário bem simples, de forma bastante lúdica. Naquela época, eu tinha uma curiosidade infantil em relação a aprender outra língua, mas minha motivação não passava disso.

A partir do ensino fundamental, já em uma instituição privada, passei a estudar inglês como uma disciplina regular. Eu me aplicava à matéria como a qualquer outra, ainda sem um interesse particular na língua. As aulas priorizavam o ensino gramatical, com algumas atividades esporádicas de escrita e pronúncia. Apesar disso, reconheço que o ensino que recebi nesse período foi bastante sólido em relação à gramática, e que essa base foi muito importante na próxima etapa dos meus estudos de inglês.

Foi no fim do ensino fundamental que eu passei a assistir o seriado norte-americano 
Os Simpsons, na época exibido nas manhãs da TV Globo. Rapidamente eu me tornei fã dos diálogos rápidos e das piadas politicamente incorretas que o show disparava em ritmo acelerado. Certo dia, eu ativei o recurso de CC (closed caption ou legenda oculta) da minha televisão e descobri que as legendas exibidas eram as originais, em inglês. Foi comparando os diálogos em português com o que eu conseguia compreender das legendas em inglês que eu percebi as adaptações que eram feitas para que a dublagem "encaixasse" com a animação. Várias piadas se perdiam no processo, e isso foi, de certa forma, gratificante para mim. Era a primeira vez que meu conhecimento de inglês me possibilitou ter acesso a algo que, se eu não soubesse um pouco da língua, passaria despercebido.

Outra experiência marcante de contato com a língua inglesa aconteceu através de um DVD da banda norte-americana de rock Linkin Park. Emprestado por um amigo, o disco continha vários clipes da banda, legendados em inglês. Eu passei a cantar junto com as músicas (que misturavam partes de rock pesado e versos de rap cantados rapidamente), um hábito que eu mantive por muito tempo. Em várias das letras, havia trechos de que eu não conseguia apreender o sentido, mas eu conseguia ouvir todas as palavras que os vocalistas cantavam. Esse foi meu primeiro esforço ligado à cognição do inglês, que em si só era bastante divertido para mim.

Outro aspecto importante do meu contato com a língua inglesa tem a ver com videogames. Desde pequeno eu sempre gostei de jogar todos os tipos de jogos a que eu tinha acesso, e praticamente todos eram em inglês. Eu me lembro de várias situações em que eu tive que procurar no dicionário inglês-português o significado de alguma palavra para poder entender o que eu devia fazer para avançar no jogo. Hoje, minha habilidade com a língua me permite não só entender melhor esses aspectos mais práticos dos jogos, mas também apreciar os enredos em que eles são baseados (que estão, por sinal, entre algumas das histórias mais criativas e comoventes com que eu já tive contato).

Em um dos anos do ensino médio, tive uma professora de inglês bastante exigente, que tinha a fama de reprovar vários alunos. Eu não enfrentei dificuldades na sua matéria, mas essa foi uma das épocas em que estudei formalmente a língua com mais afinco. A partir do ensino médio, deixei de assistir filmes dublados - quando tinha escolha. Eu passei a aproveitar todas as oportunidades que eu tinha de ter contato com a língua, o que aguçou bastante o meu ouvido para o inglês.

Quando ingressei no ensino superior, no Curso de Comunicação Social, eu comecei a pensar o conhecimento da língua inglesa como uma ferramenta essencial para me inserir no mercado de trabalho. Seguindo um conselho de um parente com experiência na área de Jornalismo, me matriculei em um curso de inglês. Lá eu tive uma experiência muito proveitosa, o professor era bastante amigável, as aulas eram baseadas em conversação e na ampliação de vocabulário. Eu frequentei o curso por 6 meses, um dos períodos em que meu inglês se desenvolveu mais intensamente.

Foi nesse momento, também, que eu passei a ter acesso a um computador conectado à Internet em casa. A partir daí, eu passei a assistir shows de TV norteamericanos e britânicos com frequência (sempre legendados em inglês), hábito que eu mantenho até hoje. Ter acesso a diferentes produções de diferentes gêneros foi útil para eu ter uma compreensão melhor da extensão dos usos da língua inglesa, além de um ótimo exercício de listening. Minha habilidade de leitura começou a ser treinada também em virtude do meu interesse em seriados. Muitas vezes, um episódio de uma série me 
deixaria inquieto e/ou confuso, porque eu não entendia bem o que aconteceu na história. Então, eu acessava sites norte-americanos em que eram publicados reviews dos episódios, além de discussões sobre o seu conteúdo. Ler esses reviews era às vezes um desafio, porque neles eu encontrava estruturas ou palavras que eu não conhecia. Para preencher essas lacunas, eu usava dicionários online e o meu próprio conhecimento sobre o enredo da série em questão.

Foi pela Internet que eu me aproximei do stand-up comedy, um dos meus gêneros favoritos de expressão artística. Eu passei a assistir pequenos clipes de produções de comediantes como George Carlin, Louis C.K., Chris Rock, Brian Regan, Bill Hicks, Richard Pryor e outros, o que era bastante divertido. Daí eu comecei a buscar os especiais inteiros desses comediantes, que muitas vezes não possuíam legendas - nem em inglês. Ter que entender o que o comediante falava sem o auxílio das legendas, além de decifrar o sentido das piadas, muitas vezes baseadas em jogos de palavras em inglês e elementos da cultura norte-americana, foi o que eu hoje encaro como uma das atividades que mais desenvolveu minha habilidade com o inglês. Além disso, as reflexões sobre a língua, realizadas principalmente por George Carlin, foram parte do motivo pelo qual eu escolhi cursar Letras Modernas, depois de abandonar o curso de Comunicação Social.

Entre o abandono do curso de Comunicação e a entrada no curso de Letras Modernas, eu passei quase um ano sem estudar ou trabalhar, período em que eu passei a maior parte do tempo em casa. Foi nessa época que eu aprendi inglês de uma forma mais ativa. Meu objetivo passou a ser melhorar meu inglês usando algumas das ferramentas que eu aprendi no curso de idiomas. Logo eu tive contato com vários canais do Youtube relacionados a assuntos que me interessavam (sempre sem legendas, vale acrescentar). Esse aspecto da minha experiência como aprendiz de inglês é interessante: a língua inglesa sempre esteve ligada a uma tópico de que eu gostava (comédia, videogames, música, shows de TV), até que ela própria se tornou um interesse.

Um dos canais que eu passei a assistir (e que eu acompanho até hoje) é chamado Game Grumps. Nele, dois jovens norte-americanos jogam videogames de várias épocas enquanto conversam, fazem piadas, se divertem ou ficam raivosos com os jogos. O humor escrachado e às vezes grotesco e infantil da dupla me forneceu várias horas de diversão ao longo dos mais de 700 vídeos do canal que eu já assisti. Mas a característica relacionada a aprendizagem de inglês no meu contato com o Game Grumps vêm do caráter de improviso dos vídeos. Não existe um roteiro estabelecido, os integrantes interrompem um ao outro, discutem e até brigam de uma forma muito próxima da oralidade. Para conseguir entender uma conversa, é preciso uma atenção diferenciada da necessária para se compreender um filme baseado em um roteiro bem definido, por exemplo.

Foi nesse período que eu comprei um Kindle, um livro digital. Através dele, eu passei a ler livros inteiros em inglês, algo que parecia muito inacessível antes. Ler livros de autores como Neil Gaiman, Richard Dawkins, George Carlin e Stephen Colbert na língua em que foram originalmente escritos foi - e ainda é - um desafio muito gratificante.

Talvez por ter tido tanto contato com produções culturais de outros países, tenho muita vontade em morar em um país falante de língua inglesa por algum tempo. Tenho certeza que o contato diário e ininterrupto com a língua desenvolverá minha habilidade com o inglês de uma forma bastante especial. Além disso, a inserção em uma cultura 
diferente da minha tem o potencial de ser uma experiência pessoal muito enriquecedora, que pode pôr em perspectiva meus conhecimentos sobre a minha própria cultura.

Eu tenho contato com a língua inglesa praticamente todos os dias. $\mathrm{Na}$ maioria das vezes, eu não faço um esforço consciente de buscar ouvir ou ler algo em inglês. A língua já está tão integrada à minha rotina que o contato acontece de forma espontânea. Apesar disso, reconheço que preciso praticar mais as habilidades de speaking e writing, o que já comecei a fazer com certa frequência no curso de Letras Modernas.

A narrativa em análise é rica em questões passíveis de investigação. Poderíamos examinar as diferentes motivações do narrador para aprender Inglês ao longo da sua vida, explorar a relação entre artefatos culturais e aprendizagem da língua inglesa, averiguar as dificuldades enfrentadas pelo aprendiz e como este as contorna, etc. Escolhemos, no entanto, centrar a nossa análise na tríade autonomia / propiciamentos / uso de tecnologias por esse ter sido o conjunto de elementos que se sobrepuseram na primeira leitura da narrativa pelo sujeito/pesquisador.

Notamos que o aprendiz estrutura seu texto ao redor dos diferentes contatos que teve com a língua inglesa durante sua vida. Valendo-se de diferentes momentos e experiências da sua vida escolar (do ensino fundamental ao ensino superior). Desse modo, o narrador apresenta uma linha do tempo, que contém momentos que considera importantes na sua relação com a língua inglesa. Estruturar o texto dessa forma foi uma escolha do autor da narrativa. Para Mota (2010) e Rajagopalan (2010), o aprendiz se vale da liberdade intrínseca ao gênero narrativa de aprendizagem para expressar sua relação com o Inglês da maneira que lhe parece mais oportuna.

\section{Autonomia}

A análise que fazemos na presente seção parte de uma definição de autonomia como sendo um sistema complexo (PAIVA, 2006) em que o aprendiz gradualmente se torna mais responsável por sua aprendizagem (HOLEC, 1981), e que envolve fatores como conscientização do aprendiz sobre o seu papel dentro do processo de ensino-aprendizagem 
da língua (SCHARLE; SZABÓ, 2000) e as escolhas feitas pelo aprendiz sobre determinados aspectos da sua aprendizagem dentro e fora da sala de aula (PAIVA, 2006).

Ao longo da narrativa, lidamos com situações em que o autor demonstra que sua aprendizagem da língua se dá de diversas formas. Certos acontecimentos narrados ao longo da sua escrita deixam entrever o caráter autônomo da sua aprendizagem. A seguir, selecionamos três excertos da narrativa e relacionamos as experiências narradas com alguns aspectos de uma aprendizagem autônoma, a saber: tomadas de decisão do aprendiz, conscientização sobre o processo de ensino-aprendizagem, avaliação da aprendizagem, planejamento dos estudos e o papel do professor na promoção da autonomia do aprendiz.

Consideremos o seguinte trecho:

Excerto 1: A partir do ensino médio, deixei de assistir filmes dublados - quando tinha escolha. Eu passei a aproveitar todas as oportunidades que eu tinha de ter contato com a língua, o que aguçou bastante o meu ouvido para o inglês.

O aprendiz localiza, na sua trajetória no ensino formal, o momento em que tomou a decisão de "aproveitar" situações de possível contato com o Inglês. Essa tomada de decisão revela a vontade do aprendiz em se responsabilizar pela própria aprendizagem, uma das marcas de uma aprendizagem autônoma. Ao invés de limitar-se ao input oferecido em sala de aula, o aprendiz escolhe expandir seu contato com a língua inglesa, e afirma que isso contribuiu para o desenvolvimento da sua habilidade de compreensão auditiva da língua (listening).

Além disso, o narrador demonstra possuir uma percepção clara de que precisava exercitar sua capacidade de listening. Tal constatação, por si só, é reveladora do caráter autônomo de sua relação com a língua inglesa. Como nos apontam Scharle e Szabó (2000), aprendizes autônomos "podem formular uma ideia sobre seu nível de proficiência: 
descobrir pontos fracos e pontos fortes, e planejar a direção do seu progresso (") (SCHARLE; SZABÓ, 2000, p. 8: tradução nossa). No excerto 1, observamos que o narrador percebe um ponto fraco em seu conhecimento do Inglês, e toma uma atitude consciente na tentativa de sanar esse problema.

Outra manifestação da consciência do aprendiz sobre o seu próprio processo de aprendizagem se encontra no Excerto 2, transcrito a seguir:

Excerto 2: Ter que entender o que o comediante falava sem o auxílio das legendas, além de decifrar o sentido das piadas, muitas vezes baseadas em jogos de palavras em inglês e elementos da cultura norte-americana, foi o que eu hoje encaro como uma das atividades que mais desenvolveu minha habilidade com o inglês.

No excerto 2, ao relacionar os esforços cognitivos para entender piadas provindas de um outro contexto cultural ao desenvolvimento das suas habilidades com a língua, o aprendiz mais uma vez evidencia estar atento ao seu processo de aprendizagem. O aprendiz avalia o efeito das dificuldades que enfrentou na sua tentativa de entender as piadas do comediante a que assistia como algo que surtiu efeito positivo sobre a sua aprendizagem. Assim, temos retratada a aplicação de uma estratégia metacognitiva de avaliação da aprendizagem, que envolve "planejar, monitorar e checar os resultados da aprendizagem" (O’MALLEY; CHAMOT, 1990, p. 144: tradução nossa). Acreditamos que o uso de estratégias metacognitivas de aprendizagem seja um indicador da autonomia do aprendiz, uma vez que deixa transparecer a responsabilidade que o aprendiz atribui a si mesmo no contexto da aprendizagem, ao refletir sobre sua própria maneira de estudar (CRUZ, 2005).

No trecho a seguir, o aprendiz narra um momento de sua vida em que estar distante da sala de aula não o impede de continuar o seu processo de aprendizagem da língua - na verdade, ele se vale desse período para aprender Inglês "de uma forma mais ativa".

${ }^{6}[\ldots .$.$] they can formulate an idea of their level of proficiency: discover weak and strong points and plan the direc-$ tions of progress.

${ }^{7}[\ldots]$ planning, monitoring, and checking the outcomes of learning. 
Excerto 3: Foi nessa época que eu aprendi inglês de uma forma mais ativa. Meu objetivo passou a ser melhorar meu inglês usando algumas das ferramentas que eu aprendi no curso de idiomas. Logo eu tive contato com vários canais do Youtube relacionados a assuntos que me interessavam (sempre sem legendas, vale acrescentar). Esse aspecto da minha experiência como aprendiz de inglês é interessante: a língua inglesa sempre esteve ligada a um tópico de que eu gostava (comédia, videogames, música, shows de TV), até que ela própria se tornou um interesse.

Para a análise do Excerto 3, consideremos o momento em que o narrador declara: "Meu objetivo passou a ser melhorar meu inglês usando algumas das ferramentas que eu aprendi no curso de idiomas". Primeiro, o aprendiz deixa claro que possuía um objetivo a ser alcançado durante o período que passaria em casa: “melhorar meu Inglês". Apesar da terminologia vaga, pode-se perceber que o autor da narrativa estabelece um objetivo orientador dos seus esforços de aprendizagem da língua. Além disso, ele reconhece a importância do que chama de "ferramentas" para os seus estudos. Dessa forma, o narrador o uso da estratégia metacognitiva de auto-gerenciamento para sua aprendizagem do Inglêsestratégia em que se estabelece uma compreensão das condições que beneficiam a aprendizagem (CRUZ, 2005).

Logo em seguida, o aprendiz afirma que seus esforços para aperfeiçoar seu domínio da língua inglesa seriam pautados em "algumas das ferramentas [aprendidas por ele] no curso de idiomas". Aqui, o autor da narrativa demonstra a influência que o curso de idiomas teria em seu estudo autônomo da língua. Pode-se inferir que tais ferramentas/estratégias de aprendizagem tenham sido apresentadas ao aprendiz pelo professor do curso de idiomas; logo, vê-se aqui refletida a influência da figura do professor sobre a autonomia dos seus alunos. Scharle e Szabó (2000) tratam de tal influência ao denotarem a importância de atividades docentes em que os professores ajudam seus alunos a exercitar suas capacidades de utilizar estratégias de aprendizagem. Assim, no excerto 3, vemos que essa ajuda se dá de forma indireta, com o aprendiz utilizando, fora da sala de aula, as estratégias apresentadas a ele pelo professor. 
A seguir, apresentamos considerações sobre a relação ambiente/aprendiz e suas conexões com a aprendizagem autônoma de Inglês.

\section{Propiciamentos}

Ao estruturar seu texto de forma cronológica, o autor da narrativa discute os propiciamentos encontrados ao longo da sua trajetória. Consideremos o trecho a seguir:

Excerto 4: A partir do ensino fundamental, já em uma instituição privada, passei a estudar inglês como uma disciplina regular. Eu me aplicava à matéria como a qualquer outra, ainda sem um interesse particular na língua. As aulas priorizavam o ensino gramatical, com algumas atividades esporádicas de escrita e pronúncia. Apesar disso, reconheço que o ensino que recebi nesse período foi bastante sólido em relação à gramática, e que essa base foi muito importante na próxima etapa dos meus estudos de inglês.

Ao versar sobre sua experiência com a disciplina de Inglês no ensino fundamental, o aprendiz revela que ainda não possuía, nesse momento, um "interesse particular na língua". Acreditamos que as práticas de ensino descritas no excerto 4 possam ter contribuído para a oferta de menos oportunidades de engajamento e participação para o aprendiz. Não há, no excerto em análise, uma motivação específica do narrador para a aprendizagem do Inglês, e pode-se afirmar que o ambiente escolar nesse momento não propiciou um contato significativo com a língua. $\mathrm{O}$ aprendiz, entretanto, ao refletir durante a redação da sua narrativa, confere um valor positivo a essa fase de sua vida escolar. Ele reconhece que o estudo gramatical da língua realizado nessa época seria aproveitado nos seus próximos encontros com a língua, um dos quais é brevemente explanado no excerto a seguir:

Excerto 5: Em um dos anos do ensino médio, tive um professora de inglês bastante exigente, que tinha a fama de reprovar vários alunos. Eu não enfrentei dificuldades na sua matéria, mas essa foi uma das épocas em que estudei formalmente a língua com mais afinco. 
No excerto 5, percebemos que a motivação para a aprendizagem da língua inglesa ainda não se origina no contato com a língua em si, mas sim com fatores ligados à cultura escolar. A exigência da professora motiva o aprendiz a se esforçar em seus estudos, tendo em vista sua vontade de não ser reprovado. O valor desse tipo de motivação é questionável, visto que, sob esse tipo de relação, o aprendiz pode não perceber a língua como um meio de comunicação a ser usado em situações de fala. Atentar-se para a motivação dos alunos é fundamental, visto que "as emoções cumprem papel relevante na aprendizagem e se ligam a questões caras ao cotidiano do professor" (ARAGÃO, 2008, p. 296). Em casos extremos, pode criar-se uma espécie de bloqueio do aprendiz com a língua, em que experiências ruins em sala de aula inibem contatos futuros com o Inglês.

Mais uma vez, observamos que o propiciamento escolar está ligado ao estudo gramatical e formal da língua. Ainda que relevante, tal estudo não é suficiente para resultar em um usuário fluente na língua. Os fatores para se chegar a tal fluência são buscados pelo aprendiz em outros ambientes que não a sala de aula. Aqui, a atitude do aprendiz em buscar diferentes ambientes e propiciamentos para a aprendizagem do Inglês evidencia o caráter autônomo do seu estudo da língua.

Paiva (2010, p. 156) explana tal fenômeno de forma muito clara, ao afirmar que “[...] a sala de aula na visão dos aprendizes, geralmente, não oferece os propiciamentos necessários para a aquisição de uma outra língua”. Diante dessa situação, ainda segundo a autora, "os aprendizes vão em busca de propiciamentos que lhes estimulem a agir, seja pela interação com outro falantes, seja pela emoção estética, seja pela ludicidade, ou pela busca de informação” (p. 156-157). Tais estímulos estão presentes nas motivações listadas pelo narrador, principalmente quando ele trata dos seus interesses em comédia, videogames, música e shows de TV.

O ambiente da sala de aula é apresentado mais uma vez no trecho a seguir, mas a partir de uma ótica diferente:

Excerto 6: Seguindo um conselho de um parente com experiência na área de Jornalismo, me matriculei em um curso de inglês. Lá eu 
tive uma experiência muito proveitosa, o professor era bastante amigável, as aulas eram baseadas em conversação e na ampliação de vocabulário. Eu frequentei o curso por 6 meses, um dos períodos em que meu inglês se desenvolveu mais intensamente.

Podemos perceber que no excerto 6 a experiência do aprendiz em um curso de línguas é narrada de forma a estabelecer uma clara diferenciação entre as aulas de Inglês da escola regular e as aulas de Inglês do curso. Dentre os aspectos listados, o foco na oralidade merece atenção especial, uma vez que, no curso de Inglês, o aprendiz encontrou o propiciamento da modalidade oral da língua que não obteve no ensino regular. Valendo-se dos conhecimentos gramaticais e estruturais da língua obtidos anteriormente, o aprendiz, ao inserir-se em um ambiente de uso concreto da língua, desenvolve suas habilidades com o Inglês de forma mais natural, sem estar sob a pressão de obter boas notas, ou de ter que agradar um professor demasiadamente exigente.

Na próxima seção, nos dedicamos ao exame da relação entre o uso de tecnologias e a aprendizagem de Inglês descrita na narrativa em análise.

\section{Uso de tecnologias digitais}

As inovações tecnológicas das últimas décadas tiveram um forte impacto no processo de ensino-aprendizagem de línguas, por possibilitar o contato do aprendiz com "representações diferenciadas da linguagem, acrescentando a imagem, o som, por exemplo" (FEISTAUER, 2013, p. 74).

No trecho a seguir, temos um exemplo de uso da tecnologia favorecendo o contato do aprendiz com o aspecto oral da língua:

Excerto 7: Outra experiência marcante de contato com a língua inglesa aconteceu através de um DVD da banda norte-americana de rock Linkin Park. Emprestado por um amigo, o disco continha vários clipes da banda, legendados em inglês. Eu passei a cantar junto com as músicas (que misturavam partes de rock pesado e versos de rap cantados rapidamente), um hábito que eu mantive por muito tempo. 
O contato direto com a língua, promovida pelo acesso ao DVD da banda de rock citada, é evidência do valor da tecnologia para o processo de aprendizagem. Além disso, percebemos que o aprendiz exerce sua autonomia ao se aproveitar das legendas contidas no DVD para praticar sua habilidade oral na língua.

No próximo excerto, há a presença de legendas enquanto motivadoras do interesse do aprendiz pela língua inglesa.

Excerto 8: Foi no fim do ensino fundamental que eu passei a assistir o seriado norte-americano Os Simpsons, na época exibido nas manhãs da TV Globo. Rapidamente eu me tornei fã dos diálogos rápidos e das piadas politicamente incorretas que o show disparava em ritmo acelerado. Certo dia, eu ativei o recurso de CC (closed caption ou legenda oculta) da minha televisão e descobri que as legendas exibidas eram as originais, em inglês. Foi comparando os diálogos em português com o que eu conseguia compreender das legendas em inglês que eu percebi as adaptações que eram feitas para que a dublagem "encaixasse" com a animação. Várias piadas se perdiam no processo, e isso foi, de certa forma, gratificante para mim. Era a primeira vez que meu conhecimento de inglês me possibilitou ter acesso a algo que, se eu não soubesse um pouco da língua, passaria despercebido.

Mais uma vez, temos aqui o Inglês intermediando a relação entre o aprendiz e uma manifestação cultural. O gosto do aprendiz pelo seriado Os Simpsons é anterior ao seu interesse pela língua em si. Por conta de uma eventualidade, o aprendiz passou a ter acesso às legendas originais dos episódios que assistia, e isso se converteu - com o auxílio da autonomia do narrador - em uma situação de aprendizado da língua.

É importante notar que o narrador já possuía certo interesse na língua - do contrário, o acesso às legendas não teria sido um estímulo ao contato com a língua. As legendas poderiam ter passado despercebidas, sem qualquer tipo de influência na trajetória do contato do aprendiz com o Inglês. No entanto, devido à curiosidade e disposição do aprendiz em lidar com a nova forma em que a língua se apresentava, a situação se tornou uma oportunidade de aprender a língua. Essa é uma atitude típica de um aprendiz autônomo, capaz de encontrar em seu cotidiano situações para aprender sobre a língua. 
O aprendiz pôde desenvolver de forma autônoma suas primeiras reflexões sobre o processo de tradução, e percebeu as adaptações inevitáveis que acontecem durante esse processo. O conceito de perdas em tradução já é esboçado pelo aprendiz, que entende que seus esforços de comparar as legendas na tela com a dublagem brasileira poderiam lhe dar acesso a algo que antes estava fora do seu alcance.

O próximo trecho lida com os jogos eletrônicos que fizeram parte da vida do aprendiz:

Excerto 9: Desde pequeno eu sempre gostei de jogar todos os tipos de jogos a que eu tinha acesso, e praticamente todos eram em inglês. Eu me lembro de várias situações em que eu tive que procurar no dicionário inglês-português o significado de alguma palavra para poder entender o que eu devia fazer para avançar no jogo.

O acesso a videogames em inglês é mais uma ocasião em que o Inglês se interpõe entre aprendiz e seu lazer. O interessante nesse caso é como a diversão do aprendiz com o artefato cultural que consumia estava diretamente ligada ao conhecimento da língua inglesa.

Ao perceber que o progresso no jogo seria possível apenas com a compreensão de um item lexical, o aprendiz encontra motivação para aprender sobre a língua. Em outras palavras, uma demanda externa impulsiona o aprendiz a buscar o entendimento do Inglês. O significado das palavras que o aprendiz pesquisava servia não apenas para dar continuidade ao seu divertimento com o jogo, mas também representava um gradual desenvolvimento do seu vocabulário em língua inglesa.

No excerto a seguir, há uma situação em que o uso da língua está intrinsecamente ligado ao lazer do aprendiz:

Excerto 10: Foi nesse momento, também, que eu passei a ter acesso a um computador conectado à Internet em casa. A partir daí, eu passei a assistir shows de TV norte-americanos e britânicos com frequência (sempre legendados em inglês), hábito que eu mantenho até hoje. Ter acesso a diferentes produções de diferentes gêneros foi útil para eu ter uma compreensão melhor da extensão dos usos da língua inglesa, além de um ótimo exercício de listening. Minha 
habilidade de leitura começou a ser treinada também em virtude do meu interesse em seriados. Muitas vezes, um episódio de uma série me deixaria inquieto e/ou confuso, porque eu não entendia bem o que aconteceu na história. Então, eu acessava sites norte-americanos em que eram publicados reviews dos episódios, além de discussões sobre o seu conteúdo.

No excerto de número 10, notamos que o acesso à Internet possibilita que o aprendiz tenha contato com produções audiovisuais em Inglês. Vemos, assim, o papel que o computador pode exercer como "meio para aprendizagem e prática da língua alvo" (BRAGA; SOUZA, 2000, p. 62). Percebemos uma manifestação da autonomia do aprendiz em questão, uma vez que ele deliberadamente opta por assistir aos shows legendados em inglês, aproveitando-se da oportunidade para intensificar o seu contato com a língua. Assim, tanto a leitura quanto a escrita da língua inglesa estavam sendo exercitadas enquanto o aprendiz assistia aos seriados.

Além disso, a relação do aprendiz com os seriados motiva o exercício da sua habilidade de leitura (reading). Percebemos que uma lacuna na absorção do conteúdo de uma manifestação cultural (neste caso, o enredo do seriado) é convertida, pelo aprendiz, em uma situação de aprendizagem da língua. Aqui, a autonomia do aprendiz está em identificar uma oportunidade de praticar suas habilidades de uso do Inglês - oportunidade relacionada, no excerto 10, à diversão de assistir seriados. A leitura de reviews dos seriados serve dois propósitos: o de auxiliar na fruição do enredo dos seriados pelo aprendiz e o de aperfeiçoar a habilidade de reading. Vemos tal situação como uma manifestação da "gama ampla de oportunidades para estudo independente e também acesso a insumo e prática da língua alvo" (BRAGA; SOUZA, 2000, p. 77) a que o aprendiz tem acesso ao utilizar o computador e a Internet.

\section{Considerações finais}

Como pode ser observado, a escrita de narrativas de aprendizagem proporciona a produção de dados valiosos para professores e alunos. Valendo-se da liberdade intrínseca ao gênero narrativa (MOTA, 2010; RAJAGOPALAN, 2010), ao longo deste artigo 
verificamos que o narrador explorou diferentes situações ligadas à aprendizagem da língua Inglesa ao longo da sua trajetória de vida. Tais situações, situadas tanto dentro quanto fora do ambiente escolar, se preenchem de valor à medida que se tornam motivo para que o aluno ressignifique sua própria trajetória de aprendizagem (CUNHA, 1997) e para que o professor reflita sobre "sua condição de ensino e possa, com isso, reconstruir os seus conhecimentos, fazendo com que sua prática pedagógica se torne mais consciente e [...] proveitosa" (LIMA, 2010, p. 11).

Ao longo da nossa discussão acerca da narrativa de aprendizagem, utilizamos três categorias de análise para refletir sobre a natureza dos dados produzidos pelo narrador.

A primeira delas constituiu-se das manifestações da autonomia do aprendiz. O caráter complexo da autonomia (PAIVA, 2006) foi reforçado ao encontrarmos, na trajetória do narrador, certas atitudes como o uso de estratégias metacognitivas de aprendizagem (O’MALLEY; CHAMOT, 1990) que demonstram que o aprendiz tornou-se gradualmente mais responsável por sua própria aprendizagem (HOLEC, 1981). Percebemos, assim, que as manifestações de autonomia do aprendiz excederam a categoria da mera auto-instrução, relacionando-se à sua capacidade de organização e suas tomadas de atitude para encontrar situações que possibilitassem uma aprendizagem mais efetiva da língua.

Para a segunda categoria, pautamos a relação ambiente/aprendiz caracterizada pelo conceito de propiciamento. Notamos as percepções do narrador sobre as oportunidades de engajamento e participação (VAN LIER, 2004) que ele encontrou durante o período retratado na narrativa, e percebemos a sua inquietude ao perceber que alguns dos propiciamentos encontrados não eram adequados à sua aprendizagem. Valendo-se da sua autonomia, o autor passou a buscar estímulos e contextos que o suprissem com situações de aprendizagem significativa da língua, demonstrando consciência sobre os propiciamentos a que tinha acesso e sobre a possibilidade de encontrar diferentes propiciamentos em outros ambientes (ARONIN; SINGLETON, 2012).

A terceira e última categoria relacionou situações em que o uso de tecnologias digitais se integrou aos esforços de aprendizado da língua inglesa. Salientamos as diferentes 
atitudes para com a tecnologia empreendidas pelo narrador e a relação dessas atitudes com a aprendizagem da língua inglesa. Percebemos, ao longo da narrativa, que o acesso à língua foi facilitado pelo uso de tecnologias digitais, que possibilitaram o contato do aprendiz com insumos diferentes dos oferecidos no ambiente escolar (BRAGA; COSTA, 2000). Além disso, notamos que o aprendiz aproveitou-se de diferentes recursos tecnológicos para exercer sua autonomia (PAIVA, 2006).

Além do exposto, ressaltamos que o exercício de realizar (auto)análise da própria narrativa de aprendizagem, pode ser de grande valor no processo de formação de professores, uma vez que oferece ao professor em formação a oportunidade de ressignificar suas experiências (FREITAS; GALVÃO, 2007) e as incorporar em sua identidade profissional, visto que a forma como se aprende a língua deixa "marcas indeléveis" (ROMERO, 2008, p. 417) sobre a figura do professor em formação.

\title{
ENGLISH LEARNING: A (SELF) ANALYSIS
}

\begin{abstract}
This paper aimed at making a (self)analysis of an English language learning narrative written at the moment in which the author initiated his studies in a Liberal Arts Program. During this (self)analysis, we mobilized concepts related to three categories of analysis: a) manifestations of the learner's autonomy; b) affordances evidenced in the relationship between the learner and the learning environments; c) situations in which the use of digital technology was integrated to the learning of the English language. We noticed, with the selection of representative excerpts of the narrative, that the narrator gradually became more autonomous in relation to his own learning, during his trajectory, choosing technological resources and learning environments better suited for his taste and motivation to learning the language. The self-analysis provided the opportunity, for the author of the narrative, to resignify his trajectory of learning and to reflect on how his English learning experience can influence his professional performance as a teacher.
\end{abstract}

KEYWORDS: Affordances; Autonomy, Learning Narratives; Usage of digital technologies.

\section{REFERÊNCIAS}

ARAGÃO, Rodrigo. Emoções e pesquisa narrativa: transformando experiências de aprendizagem. Revista Brasileira de Linguística Aplicada, Belo Horizonte, v. 8, p. 295-320, 2008. 
ARONIN, Larissa; SINGLETON, David. Affordance theory in multilingualism studies. Studies in Second Language Learning and Teaching, Kalisz: Universidade Adam Mickiewicz, v. 2, n. 3, p. 311-331, 2012.

BENSON, Phil; VOLLER, Peter (Org.). Autonomy and independence in language learning teaching. London e New York: Longman, 1997.

BRAGA, Denise Bértoli; COSTA, Lúcia Alves. O computador como instrumento e meio para ensino e aprendizagem de línguas. Trabalhos em Linguística Aplicada, Campinas, v. 36, Jul/Dez, p. 61-79, 2000.

CRUZ, Giêdra Ferreira. A Contribuição das estratégias metacognitivas para o desenvolvimento da autonomia do aprendiæ: 160 f. (Dissertação de mestrado em Letras). Instituto de Letras da Universidade Federal da Bahia, Salvador, 2005.

CUNHA, Maria Isabel da. Conta-me agora!: As narrativas como alternativas pedagógicas na pesquisa e no ensino. Revista da Faculdade de Educação, São Paulo, v. 23, n. 1-2, jan. 1997.

DICKINSON, Leslie. Learner autonomy: what, why and how? In: LEFFA, V. (Org.) $A u$ tonomy in language learning. Porto Alegre: Editora da Universidade - UFRGS, p. 2-12, 1994.

FEISTAUER, Cláudia Madalena. Novas Tecnologias na Alfabetização de Jovens e Adultos: relato de experiência como formadora do TOPA. In: BARRETO, Aparecida Brito; BRENNAND, Edna Gusmão. (Org.). Perspectivas interdisciplinares sobre educação e tecnologias. 1. ed., João Pessoa: Editora: UFPB, 2013. p. 65-78.

FREITAS, Denise de; GALVÃO, Cecília. O uso de narrativas autobiográficas no desenvolvimento profissional de professores. Ciências \& Cognição. Rio de Janeiro: UFRJ, v. 12, p. 1-12, 2007.

GIBSON, James Jerome. The ecological approach to visual perception. Hillsdale, NJ: Lawrence Erlbaum, 1986.

GOMES, Camila Belmonte Martinelli; SOUZA, Valeska Virgínia Soares. Dispositivos móveis e seus propiciamentos: caminhos para a aprendizagem ubíqua de língua inglesa. Polifonia, Cuiabá-MT, v. 24, n. 35/2, p. 68-88, jan./jun. 2017

HOLEC, Henri. Autonomy in foreign language learning. Oxford: Pergamon, 1981.

KORDT, Birgit. Affordance theory and multiple language learning and teaching, International Journal of Multilinguism, v. 15, n. 2, p. 135-148, 2016.

LIMA, Diógenes Cândido de. Aprendizagem de língua inglesa: histórias refletidas. Vitória da Conquista: Edições Uesb, 2010.

LITTLE, David: Language Learner Autonomy: Some Fundamental Considerations Revisited. Innovation in Language Learning and Teaching. V. 1, n. 1, p. 14-29, 2007. 
LUZ, Emeli Borges Pereira. A Autonomia no processo de ensino e aprendizagem de línguas em ambiente virtual (teletandem). (Dissertação de Mestrado). Universidade Estadual Paulista "Júlio de Mesquita Filho. São José do Rio Preto: São Paulo, 2009.

MOTA, Kátia Maria Santos. Narrativas autobiográficas, percursos de aprendizagem da língua estrangeira. In: LIMA, Diógenes Cândido de. (Org.). Aprendizagem de língua inglesa: histórias refletidas. Vitória da Conquista: Edições UESB, 2010. p. 185-200.

O’MALLEY, J. Michael.; CHAMOT, Anna Uhl. Learning Strategies in Second Language Acquisition. Cambridge: Cambridge University Press, 1990.

PAIVA, Vera Lúcia Menezes de Oliveira e. Como se aprende uma língua estrangeira? In: ANASTÁCIO, Elismar Bertoluci de Araúko; MALHEIROS, Márcia Rita Trindade Leite; FIGLIOLINI, Márcia Cristina Rocha. (Orgs.). Tendências contemporâneas em Letras. Campo Grande: Editora da UNIDERP, 2005. p. 127-140.

2006, p.78-127.

Autonomia e complexidade. Linguagem \& Ensino (UCPel), Pelotas, v. 9, n.1,

. Propiciamento (affordance) e autonomia na aprendizagem de língua inglesa. In: LIMA, Diógenes Cândido de. (Org.). Aprendizagem de língua inglesa: histórias refletidas. Vitória da Conquista: Edições UESB, 2010, p. 151-161.

O uso da tecnologia no ensino de línguas estrangeiras. In: Jesus, Dánie Marcelo de; Maciel. Ruberval Franco. (Org.). Olhares sobre tecnologias digitais: linguagens, ensino, formação e prática docente, Coleção: Novas Perspectivas em Linguística Aplicada. 1.ed., Campinas: Pontes, 2015, v. 44, p. 21-34.

PINHO, Isis da Costa; LIMA, Marilia dos Santos. Teacher's digital fluency: a new competence for foreign language teaching. Revista Brasileira de Linguistica Aplicada, v. 13, p. 711739, 2013.

RAJAGOPALAN, Kanavillil. Narrando as Narrativas: de le grand récit a la petite histoire. In: LIMA, D. C. (Org.). Aprendizagem de língua inglesa: histórias refletidas. Vitória da Conquista: Edições UESB, 2010. p. 13-18.

ROMERO, Tania Regina de Souza. Linguagem e memória no construir de futuros professores de inglês. Revista Brasileira de Linguística Aplicada, Belo Horizonte, v. 8, p. 401-420, 2008.

SANTOS, Lucas Moreira dos Anjos; KADRI, Michele Salles El; GAMERO, Raquel; GIMENEZ, Telma. Teaching English as an additional language for social participation: digitaltechnology in an immersion programme. Revista Brasileira de Linguística Aplicada, Belo Horizonte, v. 18, n. 1, p. 29-55, 2018.

SCHARLE, Ágota; SZABÓ, Anita. Learner autonomy: A guide to developing learner responsibility. 1 ed. Cambridge: University Press, 2000. 
VAN LIER, Leo. The ecology and semiotics of language learning: a sociocultural perspective. Boston: Kluwer Academic Publishers, 2004.

Recebido em: 12/08/2018.

Aprovado em: 02/02/2019. 